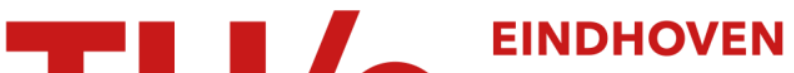

\section{Single-photon experiments at telecommunication wavelengths using nanowire superconducting detectors}

Citation for published version (APA):

Zinoni, C., Alloing, B., Li, L., Marsili, F., Fiore, A., Lunghi, L., Gerardino, A., Vakhtomin, Y., Smirnov, K. V., \& Gol'tsman, G. N. (2007). Single-photon experiments at telecommunication wavelengths using nanowire superconducting detectors. Applied Physics Letters, 91(3), 031106-1/3. [031106].

https://doi.org/10.1063/1.2752108

DOI:

$10.1063 / 1.2752108$

Document status and date:

Published: 01/01/2007

\section{Document Version:}

Publisher's PDF, also known as Version of Record (includes final page, issue and volume numbers)

\section{Please check the document version of this publication:}

- A submitted manuscript is the version of the article upon submission and before peer-review. There can be important differences between the submitted version and the official published version of record. People interested in the research are advised to contact the author for the final version of the publication, or visit the $\mathrm{DOI}$ to the publisher's website.

- The final author version and the galley proof are versions of the publication after peer review.

- The final published version features the final layout of the paper including the volume, issue and page numbers.

Link to publication

\section{General rights}

Copyright and moral rights for the publications made accessible in the public portal are retained by the authors and/or other copyright owners and it is a condition of accessing publications that users recognise and abide by the legal requirements associated with these rights.

- Users may download and print one copy of any publication from the public portal for the purpose of private study or research.

- You may not further distribute the material or use it for any profit-making activity or commercial gain

- You may freely distribute the URL identifying the publication in the public portal.

If the publication is distributed under the terms of Article 25fa of the Dutch Copyright Act, indicated by the "Taverne" license above, please follow below link for the End User Agreement:

www.tue.nl/taverne

Take down policy

If you believe that this document breaches copyright please contact us at:

openaccess@tue.nl

providing details and we will investigate your claim. 


\title{
Single-photon experiments at telecommunication wavelengths using nanowire superconducting detectors
}

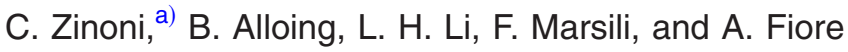 \\ Ecole Polytechnique Fédérale de Lausanne (EPFL), CH-1015 Lausanne, Switzerland \\ L. Lunghi and A. Gerardino \\ Institute of Photonics and Nanotechnology, CNR, via del Cineto Romano 42, 00156 Roma, Italy
}

Yu. B. Vakhtomin, K. V. Smirnov, and G. N. Gol'tsman

Moscow State Pedagogical University, 29 M. Pirogovskaya Str., 119891 Moscow, Russia

(Received 9 November 2006; accepted 3 June 2007; published online 19 July 2007)

\begin{abstract}
The authors report fiber-coupled superconducting single-photon detectors with specifications that exceed those of avalanche photodiodes, operating at telecommunication wavelength, in sensitivity, temporal resolution, and repetition frequency. The improved performance is demonstrated by measuring the intensity correlation function $g^{(2)}(\tau)$ of single-photon states at $1300 \mathrm{~nm}$ produced by single semiconductor quantum dots. (C) 2007 American Institute of Physics.
\end{abstract}

[DOI: $10.1063 / 1.2752108]$

While silicon-based avalanche photodiodes (APDs) can be used as single-photon detectors in the visible wavelength range, a mature technology with single-photon sensitivity is still lacking at telecommunication wavelengths $(1310-1550 \mathrm{~nm})$. The poor performance of InGaAs APDs barely satisfies the requirements for secure quantum key distribution, limiting the maximum distance, and sifted key rate. More generally, progress in the development of systems based on processing and measuring photonic quantum bits at these wavelengths is hindered by the lack of adequate detectors. As an example, while single-photon sources based on semiconductor quantum dots (QDs) have been extensively characterized at wavelength $<1000 \mathrm{~nm}$, only a few clear demonstrations of single-photon emission have been reported at $1300 \mathrm{~nm} .{ }^{1,2}$ The recent development of singlephoton detectors based on $\mathrm{NbN}$ superconducting nanostructures, ${ }^{3}$ promises orders of magnitude improvement over InGaAs APDs in sensitivity, dark count, jitter, and repetition frequency. In the following we report on fiber-coupled superconducting single-photon detectors (SSPDs) with sensitivity several orders of magnitude larger than InGaAs APDs, and demonstrate their application to single-photon measurements at telecommunication wavelengths. The detection principle of the SSPDs is based on the local inhibition of superconductivity in a current-biased ultrathin superconducting nanowire due to the absorption of a light quantum. ${ }^{4}$ The SSPDs used in this work consist of $10 \times 10 \mu \mathrm{m}^{2}$ meanders made of a $100 \mathrm{~nm}$ wide, $3.5 \mathrm{~nm}$ thick $\mathrm{NbN}$ nanowire. The chips were fabricated in Moscow using the technology described in Ref. 5. The SSPD meander was aligned to the fiber core with a precision of less than a $1 \mu \mathrm{m}$ and held in place by a beryllium copper spring. After several thermal cycles no deterioration of the detector-fiber alignment was observed. The system is then cooled down to $2.3 \mathrm{~K}$ in a liquid $\mathrm{He}$ insert. Input fiber connectors and output SMA cables are mounted at room temperature on the flange of the cryogenic insert. The high frequency components of the detector output are fed to a $60 \mathrm{~dB}$ gain amplifier with a $2.5 \mathrm{GHz}$ bandwidth.

\footnotetext{
${ }^{a)}$ Electronic mail: carl.zinoni@epfl.ch
}

The efficiency of the fiber-coupled detector was measured using an attenuated gain-switched diode laser at $1300 \mathrm{~nm}$ and a calibrated InGaAs APD as a reference. The dependence of the quantum efficiency $(\mathrm{QE})$ as a function of the normalized bias current $\left(I_{b}\right)$ with respect to the critical current $\left(I_{c}=28.2 \mu \mathrm{A}\right)$ is shown along with the dark count rate (DCR) in Fig. 1(a) for the best SSPD. The QE for the SSPD refers to the percentage of single-photon pulses coupled to the fiber that produce an output signal. Both QE and dark counts increase with increasing bias current. At a bias current of $0.78 I_{c}$ an efficiency $\mathrm{QE}=4.8 \%$ and dark count rate $\mathrm{DCR}$ $=13 \mathrm{~Hz}$ are measured. The other SSPD had lower efficiency $(2.5 \%)$ for the same DCR. The corresponding QE/DCR ratios are over a factor of 10 higher than previous reports for fiber-coupled SSPDs. ${ }^{6,7}$ The plateau in the DCR, measured

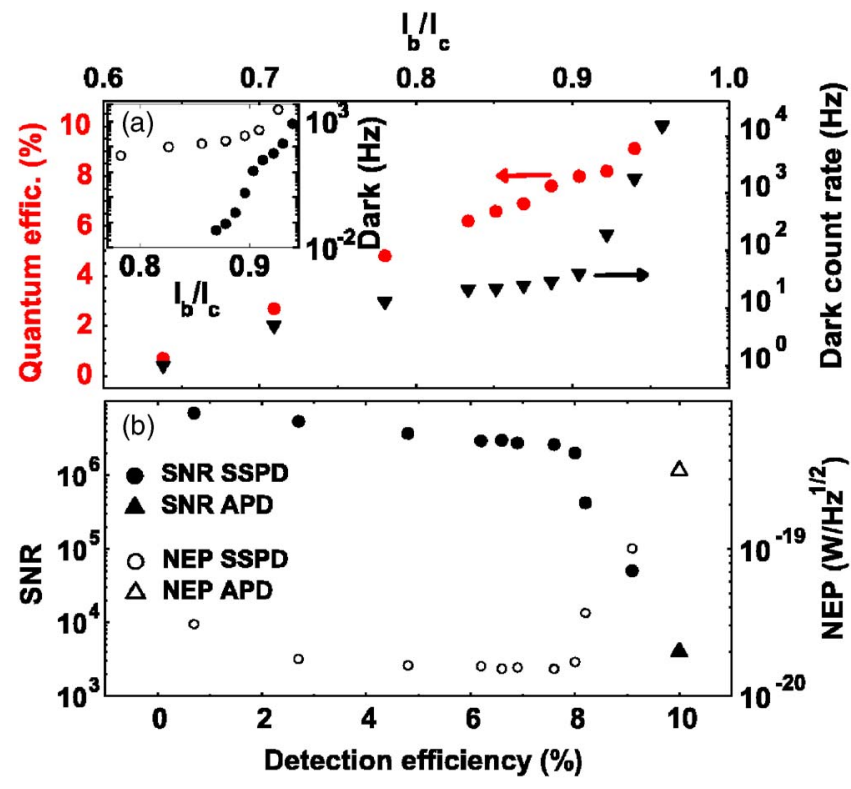

FIG. 1. (a) SSPD quantum efficiency and dark count rate plotted as a function of normalized current at $2.3 \mathrm{~K}$. Inset: dark count rate plotted as a function of normalized current for a different SSPD system with/without (filled/empty circles) cold filter. (b) Comparison between SSPD and APD performances. 


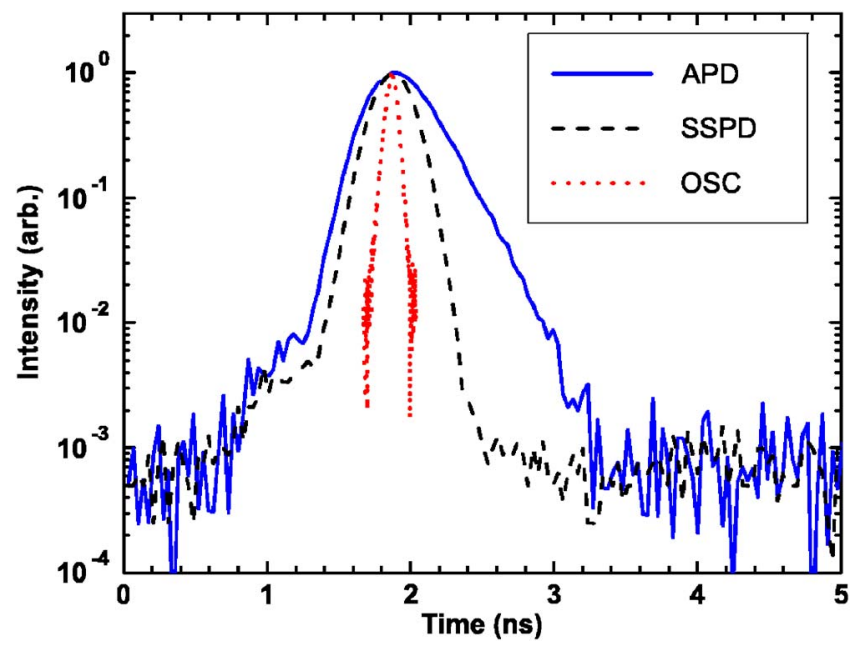

FIG. 2. Measurement of the jitter of the detectors. Dotted line: laser pulse $(\mathrm{FWHM}=88 \mathrm{ps}$ ) measured on a sampling oscilloscope with $24 \mathrm{GHz}$ bandwidth. Continuous line: temporal response of the APD (FWHM $=480 \mathrm{ps}$ ). Dashed line: temporal response of the SSPD (FWHM=320 ps).

below a bias current of $0.87 I_{c}$ [Fig. 1(a)], is attributed to background thermal radiation, at room temperature, coupled to the SSPD system through the input fiber. Without thermal radiation, the DCR would fall below $1 \mathrm{~Hz}$ at $I<0.9 I_{c}$, as previously reported. ${ }^{8}$ The plateau was not observed in previous reports ${ }^{9,8}$ as the thermal radiation was blocked in those experiments. We have experimentally verified on a different SSPD system that the excess DCR in the plateau can be eliminated by using a cold filter [inset of Fig. 1(a)].

For comparison with other detector systems we have plotted on the right axis of Fig. 1(b) the noise equivalent power (NEP) calculated for a quantum detector from the equation: ${ }^{10} \mathrm{NEP}=h \nu / \mathrm{QE} \times \sqrt{2 \mathrm{DCR}}$, where $h \nu$ is the photon energy. The NEP is an appropriate figure of merit when a low light power must be measured. A more relevant parameter, for applications where single-photon states must be detected, is given by the ratio between the probability of generating an event from the detection of a photon (the QE) and the probability of generating a dark event. ${ }^{10}$ A direct comparison between the detectors is complicated by the fact that the APDs must be operated in gated mode, so that only a dark count probability (DCP) per gate can be defined, which is a function of the gate width. Therefore we compare the performance of the SSPD and APD by defining the signal to noise ratio as $\mathrm{SNR}=\mathrm{QE} / \mathrm{DCP}$, where the $\mathrm{DCP}$ is measured for a gate width of $1 \mathrm{~ns}$. In Fig. 1(b) the SNR values for the SSPD are deduced from the data presented in Fig. 1(a) and by normalizing the dark count rate to a $1 \mathrm{~ns}$ time bin. For a fair comparison between the detectors, the dark count rate measured $\left(\mathrm{DCR}_{m}\right)$ on the APD must be normalized to the optical gate duration $(D)$ and repetition frequency $(F)$ to obtain the $\mathrm{DCR}=\mathrm{DCR}_{m} /(D F)$. The DCP (for a 1 ns gate) was calculated from a dark count rate $\mathrm{DCR}_{m}=30 \mathrm{~Hz}$, measured for a 300 ps optical gate at a repetition frequency of $4 \mathrm{MHz}$. The APD QE is $10 \%$. These values correspond to the optimized working regime used for antibunching measurements in Ref. 2. The SSPD displays several orders of magnitude improvement in the SNR.

Figure 2 reports the temporal dynamics of a laser diode pulse as measured directly using a sampling oscilloscope and by time-correlated single-photon counting (TCSPC) using Downloaded 26 Feb 2008 to 131.155.108.71. Redistribution subject

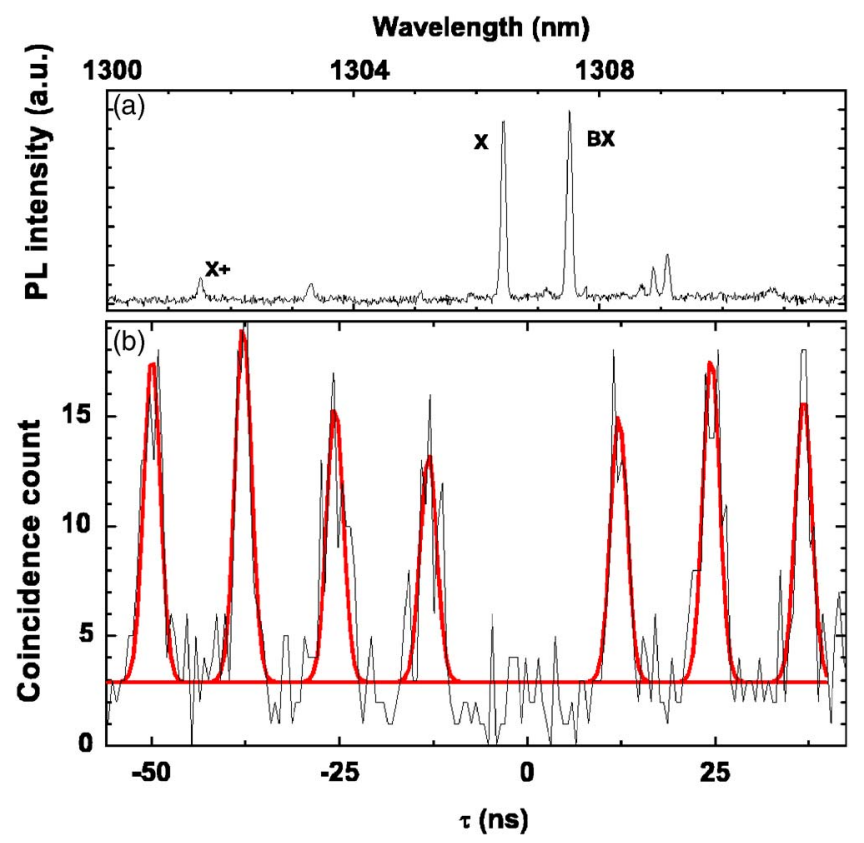

FIG. 3. (a) PL spectrum at $10 \mathrm{~K}$ from a single quantum dot showing emission of the exciton $(\mathrm{X})$, biexciton $(\mathrm{BX})$, and charged exciton $(\mathrm{X}+)$. (b) Photon autocorrelation measurement on the $\mathrm{X}$ line under pulsed excitation obtained with an integration time of $1.8 \mathrm{~h}$ and a time bin of $560 \mathrm{ps}$. Solid (red) line is a sum of Gaussians with FWHM=2.2 ns and an offset of three coincidences.

the SSPD and the APD. From the jitter characteristics of the correlation card, we estimate the time resolution of the SSPD and APD at 150 and 400 ps, respectively. Lower jitter values $\left(18\right.$ ps have been reported $\left.{ }^{11}\right)$ could be achieved by improving the amplification electronics. We note that the SSPD response follows a Gaussian distribution, while the APD presents an asymmetric profile, which depends on the count rate and limits their application for TCSPC experiments.

In order to validate the application of SSPDs to the characterization of nonclassical light states at telecommunication wavelengths, we measured the correlations between single photon pulses produced by a single InAs/GaAs quantum dot emitting at $1300 \mathrm{~nm}$. The low-density $\left(\sim 2\right.$ dots $\left./ \mu \mathrm{m}^{2}\right)$ ensemble of QDs was grown by molecular beam epitaxy at the center of a GaAs/AlAs planar microcavity, as described in Ref. 12. Circular mesas of $1.5 \mu \mathrm{m}^{2}$ diameter were defined by electron-beam lithography and reactive ion etching in order to isolate the emission of a single QD. The excitation of the QDs and light collection strategies are similar to the ones described in Ref. 2. The photoluminescence (PL) spectrum from a single QD [Fig. 3(a)] is dominated by two lines corresponding to the emission from exciton $(\mathrm{X})$ and biexciton (BX) states. As a first test we demonstrate single-photon emission from the $\mathrm{X}$ line under nonresonant pulsed excitation at $80 \mathrm{MHz}$. We remark that this repetition frequency is unachievable with APDs for a reasonable QE, which are limited to a few megahertz. The coincidence histogram [Fig. $3(b)]$ is characterized by periodic peaks separated by the laser repetition frequency except for zero delays; this is the signature of a single-photon emitter under pulsed excitation. The peaks are well fitted by Gaussian time distributions with an offset of three coincidences and a full width at half maximum $(\mathrm{FWHM})=2.2 \mathrm{~ns}$ that corresponds to twice the $\mathrm{X}$ lifetime. ${ }^{2}$ Normalizing the counts in $2.2 \mathrm{~ns}$ windows we calculate a $g^{(2)}(0)=0.18$. This value is lower than the result to AIP license or copyright; see http://apl.aip.org/apl/copyright.jsp 


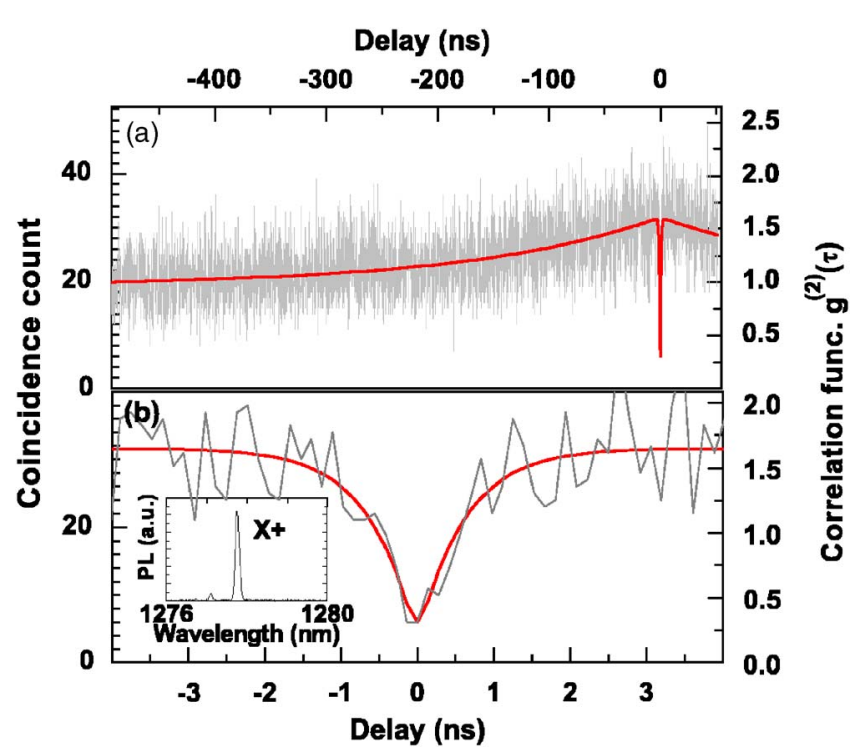

FIG. 4. (a) Measurement of $g^{(2)}(\tau)$ under resonant excitation, with a time bin of 139 ps. (b) Blow-up at short time delays demonstrating antibunching. Inset: PL spectrum of the positive trion under resonant excitation $(T=10 \mathrm{~K})$. Solid (red) line in (a) and (b) is the fit of the correlation function $g^{(2)}(\tau)$.

$\left[g^{(2)}(0)=0.38\right]$ obtained using two InGaAs APDs (Ref. 2) due to the increase of the SNR in this experiment. The coincidences between the peaks are due to uncorrelated light entering the system and detector dark counts. While these pulsed measurements allow an estimation of $g^{(2)}(0)$, which is important for applications that use single-photon sources, many important physical properties of the system are hidden in the correlation function $g^{(2)}(\tau)$ for any delay. ${ }^{13-15}$ The measurement of the $g^{(2)}(\tau)$ with APDs is exceedingly difficult since the use of relatively long $(>10 \mathrm{~ns})$ gates would drive the experimental SNR below unity. The $g^{(2)}(\tau)$ was measured on the positively charged exciton emission [inset of Fig. 4(b)] under cw excitation by pumping resonantly in the excited state of the trion. The resulting histogram, measured for a pump power of $0.2 \mathrm{~mW}$, is shown in Fig. 4(a) for long delays $(0.5 \mu \mathrm{s})$. For time delays between 3 and $200 \mathrm{~ns}$ an increase of the correlation function is observed: this bunching behavior, already studied for short-wavelength QDs, ${ }^{16}$ shows that after emission of a photon from the positive trion the QD remains charged allowing the reexcitation of the charged exciton state. For short time delays $<3 \mathrm{~ns}$ [see Fig. 4(b)], an antibunching dip is observed, confirming the sub-Poissonian statistics of the light emitted by the trion line. The bunching and antibunching behaviors can be modeled in a three level system with the following expression: ${ }^{17}$ $g^{(2)}(\tau)=1-(1+a) \times \exp (-\tau / \tau 1)+a \times \exp \left(-\tau / \tau_{2}\right)$. To account for the limited setup resolution, detection of uncorrelated photons and dark counts, we fitted the experimental data by convolving a Gaussian time distribution $(\mathrm{FWHM}=200 \mathrm{ps})$ with the correlation function corrected for noise: ${ }^{13} g_{n}^{(2)}(\tau)$ $=1+\rho\left(g^{(2)}(\tau)-1\right)$. The fit provides the values $a=0.8$, $\tau_{1}=0.62 \mathrm{~ns}, \tau_{2}=170.8 \mathrm{~ns}, \rho=0.9$, and $g^{(2)}(0)=0.18 \pm 0.02$.

In conclusion we have demonstrated the use of fibercoupled SSPDs in photon correlation experiments at telecommunication wavelength. Such experiments are a key resource in quantum optics, for example, for the character- ization of thermal light sources ${ }^{18}$ the measurement of spatial coherence, ${ }^{19}$ and in quantum coherence optical tomography. ${ }^{20}$ We thus expect that the availability of these SSPD systems will significantly improve the range of application of quantum technologies in the telecommunication wavelength range. As demonstrated the dark count can be reduced by more than one order of magnitude with appropriate filtering of the room temperature background radiation and even higher efficiencies can be achieved by integrating optical microcavities with the SSPD - up to 50 was demonstrated for free-space coupling. ${ }^{21}$ SSPDs thus have a considerable potential impact in photonics and quantum optics.

This work was supported by Swiss National Foundation through the "Professeur borsier" and NCCR Quantum Photonics program, FP6 STREP "SINPHONIA" (Contract No. NMP4-CT-2005-16433), IP “QAP” (Contract No. 15848), NOE "ePIXnet," and the Italian MIUR-FIRB program.

${ }^{1}$ M. B. Ward, O. Z. Karimov, D. C. Unitt, Z. L. Yuan, P. See, D. G. Gevaux, A. J. Shields, P. Atkinson, and D. A. Ritchie, Appl. Phys. Lett. 86, 201111 (2005).

${ }^{2}$ C. Zinoni, B. Alloing, C. Monat, V. Zwiller, L. H. Li, A. Fiore, L. Lunghi, A. Gerardino, H. de Riedmatten, H. Zbinden, and N. Gisin, Appl. Phys. Lett. 88, 131102 (2006).

${ }^{3}$ G. N. Gol'tsman, O. Okunev, G. Chulkova, A. Lipatov, A. Semenov, K. Smirnov, B. Voronov, A. Dzardanov, C. Williams, and R. Sobolewski, Appl. Phys. Lett. 79, 705 (2001).

${ }^{4}$ A. D. Semenov, G. N. Gol'tsman, and A. A. Korneev, Physica C 351, 349 (2001).

${ }^{5}$ G. N. Gol'tsman, K. Smirnov, P. Kouminov, B. Voronov, N. Kaurova, V. Drakinsky, J. Zhang, A. Verevkin, and R. Sobolewski, IEEE Trans. Appl. Supercond. 13, 192 (2003).

${ }^{6}$ R. H. Hadfield, M. J. Stevens, S. S. Gruber, A. J. Miller, R. E. Schwall, R. P. Mirin, and S. W. Nam, Opt. Express 13, 10846 (2005).

${ }^{7}$ W. Slysz, M. Wegrzecki, J. Bar, P. Grabiec, M. G. Rska, V. Zwiller, C. Latta, P. Bohi, I. Milostnaya, O. Minaeva, A. Antipov, O. Okunev, A. Korneev, S. Smirnov, B. Voronov, K. Kaurova, G. Gol'tsman, A. Pearlman, A. Cross, I. Komissarov, A. Verevkin, and R. Sobolewski, Appl. Phys. Lett. 88, 261113 (2006).

${ }^{8}$ A. Korneev, V. Matvienko, O. Minaeva, I. Milostnaya, I. Rubtsova, G. Chulkova, K. Smirnov, V. Voronov, G. Gol'tsman, W. Slysz, A. Pearlman, A. Verevkin, and R. Sobolewski, IEEE Trans. Appl. Supercond. 15, 571 (2005).

${ }^{9}$ A. Engel, A. D. Semenov, H. H.-W. Hübers, K. Il'in, and M. Siegel, Physica C 444, 12 (2006).

${ }^{10}$ A. Karlsson, M. Bourennane, G. Ribordy, H. Zbinden, J. Brendel, J. Rarity, and P. Tapster, IEEE Circuits Devices Mag. 15, 34 (1999).

${ }^{11}$ A. Verevkin, A. Pearlman, W. Słysz, J. Zhang, M. Currie, A. Korneev, G. Chulkova, O. Okunev, P. Kouminov, K. Smirnov, V. Voronov, G. Gol'tsman, and R. Sobolewski, J. Mod. Opt. 51, 1447 (2004).

${ }^{12}$ B. Alloing, C. Zinoni, V. Zwiller, L. Li, C. Monat, M. Gobet, G. Buchs, A. Fiore, E. Pelucchi, and E. Kapon, Appl. Phys. Lett. 86, 101908 (2005).

${ }^{13}$ C. Becher, A. Kiraz, P. Michler, A. Imamoglu, W. Schoenfeld, P. Petroff, L. Zhang, and E. Hu, Phys. Rev. B 63, 121312 (2001).

${ }^{14}$ D. V. Regelman, U. Mizrahi, D. Gershoni, E. Ehrenfreund, W. V. Schoenfeld, and P. M. Petroff, Phys. Rev. Lett. 87, 257401 (2001).

${ }^{15}$ E. Moreau, I. Robert, L. Manin, V. Thierry-Mieg, J. M. Gerard, and I. Abram, Phys. Rev. Lett. 87, 183601 (2001).

${ }^{16}$ C. Santori, D. Fattal, J. Vuckovic, G. S. Solomon, E. Waks, and Y. Yamamoto, Phys. Rev. B 69, 205324 (2004).

${ }^{17}$ S. C. Kitson, P. Jonsson, J. G. Rarity, and P. R. Tapster, Phys. Rev. A 58, 620 (1998).

${ }^{18}$ B. L. Morgan and L. Mandel, Phys. Rev. Lett. 16, 1012 (1966).

${ }^{19}$ R. H. Brown and R. Twiss, Nature (London) 177, 27 (1956).

${ }^{20}$ A. F. Abouraddy, M. B. Nasr, B. E. A. Saleh, A. V. Sergienko, and M. C. Teich, Phys. Rev. A 65, 053817 (2002).

${ }^{21}$ K. M. Rosfjord, J. K. W. Yang, E. A. Dauler, A. J. Kerman, V. Anant, B. M. Voronov, G. N. Gol'tsman, and K. K. Berggren, Opt. Express 14, 527 (2006). 